\title{
Application of Modified Gompertz Model to Study on Biogas production from middle temperature co-digestion of pig manure and dead pigs
}

\author{
Zhu Hongguang ${ }^{1, *}$, Yang Jing ${ }^{1}$, and Cheng Xiaowei ${ }^{1}$ \\ ${ }^{1}$ Bio-Energy Research Center,Institute of New Rural Development,Tongji University,201804 Shanghai, China
}

\begin{abstract}
The dead pig is an organic waste rich in oil and protein, and is an ideal anaerobic digestion raw material. This study based on single factor ANOVA and Modified Gompertz model. It investigated the effects of the ratio of dead pigs on biogas production by middle temperature co-digestion of pig manure and dead pigs. And the biogas production potential was determined. The results showed that there was no significant correlation between the ratio of dead pigs and the biogas production. The ratio would significantly affect the average methane content and degradation rate. When the addition ratio was in the range of 3 to $15 \%$, the biogas production was between 191.39 and 202.44 (L/ $\mathrm{kg} \mathrm{VS}$ ). The average contents of methane were $50.67 \%$, $50.35 \%, 41.83 \%, 45.53 \%$ and $44.57 \%$, respectively. The time required to reach $80 \%$ of the biogas production was $28,34,36,65$ and 63 days, respectively. The degradation rate of the raw materials was generally decreased with the increase of the addition ratio. The results of Modified Gompertz model fitting showed that the mixed raw materials had a fully anaerobic digestion with high utilization rate and short hysteresis in the range of $0 \sim 9 \%$. Therefore, a hydraulic retention time (HRT) of 30 days and the addition ratio was in the range of 0 to $6 \%$ could be recommended for a continuous digester. It could get a better gas production and higher raw material utilization.
\end{abstract}

\section{Introduction}

In the case of increasingly tight energy and increasingly serious environmental pollution, Anaerobic digestion, as an environmental engineering technology that can not only process organic waste but also produce clean energy, biogas, is receiving more and more attention [1-2]. The anaerobic digestion technology of livestock and poultry manure is widely used in China and has achieved certain achievements [3]. As of 2012, China's large and mediumsized biogas projects using livestock and poultry manure as raw materials have reached 15,000 [4]. Recent studies have shown that the energy return on energy production of anaerobic digestion of single materials is low and the economic benefits are not high. Mixed anaerobic digestion of two or more materials can overcome the shortcomings of single material digestion, improve the utilization rate of materials and improve the economic benefits of biogas projects [5], so choosing an organic waste that can be found near the farm to mix it with livestock manure can result in more benefits.

Dead pig is a kind of meat organic waste rich in oil and protein, and its output is huge, and its source is wide. For the treatment of this part of waste, the commonly used methods include deep burial, incineration, oil refining, aerobic fermentation, etc. However, these methods have some drawbacks, and it is difficult to balance both safety and economy [6]. S. Luostarinen et al. found that the anaerobic digestion of the oil sludge from the meat processing plant and the sewage sludge can obtain a higher methanogenic potential $(918 \mathrm{~m} 3 / \mathrm{t}$ VS) [7]. In principle, kitchen waste is also an organic waste rich in oil and protein, with a fat content of up to $24 \%$ and a protein content of up to $15 \%$ [8]. his content is close to the average oil content of pork in $26 \%$ and the protein content of $12.4 \%$ [9]. L. Zhang et al. research on mixed anaerobic digestion of kitchen waste and pig farm wastewater showed that mixed anaerobic digestion significantly improved biogas productivity and process stability [10]. Therefore, it is feasible to carry out mixed fermentation of sick pigs with other materials, and theoretically it is an ideal raw material for mixed anaerobic digestion with pig manure.

The Modified Gompertz model can be used to fit the relationship between cumulative gas production and fermentation time. Hu et al. used the Modified Gompertz model to fit the fermentation of Typha, and found that the hydrolysis process is the main reason for limiting the anaerobic fermentation of Typha [11]. J. C. Li et al. used this model to fit the biogas fermentation of municipal solid waste, and found that the change of cumulative gas production has a good correlation with the model, which can be used to evaluate the effect of the ratio of fermentation to fermentation and biogas fermentation [12]. Therefore, the Modified Gompertz model can be used to fit the mixed anaerobic digestion of dead pigs and pig

\footnotetext{
* Zhu Hongguang: zhuhg@,tongji.edu.cn
} 
manure, and analyse the effect of the proportion of dead pigs on the fermentation.

The previous research of the research group showed that temperature had a great influence on the anaerobic digestion of dead pigs and pig manure, and high temperature fermentation easily led to reaction failure [13]. The purpose of this study was to use single factor analysis of variance to explore the addition of dead pigs under medium temperature fermentation. The effects of anaerobic digestion of pig manure on biogas production and the fitting of the Modified Gompertz model were used to evaluate whether the dead pigs had an inhibitory effect on the anaerobic digestion of the mixed raw materials.

\section{Method}

\subsection{Collection and preparation of fermentation raw materials}

The pig manure was taken from Fumin Farm in Chongming County, Shanghai. The samples were collected for one week before being collected. They were collected and sent to the Tongji University Material and Energy Research Center Laboratory and stored in a refrigerator at $4{ }^{\circ} \mathrm{C}$. The sick pigs taken from Fumin Farm are pretreated by pulverization and high-temperature cooking to make them into a paste-like meat puree, which is kept in the refrigerator for use. In the biogas project in which the pig manure is used as a fermentation raw material in Fumin Farm, the fermentation broth is subjected to solid-liquid separation, and then the biogas residue is taken as an inoculum. The characteristics of the three were tested before the test, as shown in Table 1 .

Table 1. Characteristics of test materials.

\begin{tabular}{|c|c|c|c|}
\hline Item & $\begin{array}{c}\text { Pig } \\
\text { manure }\end{array}$ & $\begin{array}{c}\text { Dead } \\
\text { pig }\end{array}$ & Inoculum \\
\hline $\begin{array}{c}\text { Total solids content } \\
\text { (TS, \%) }\end{array}$ & 19.50 & 50.03 & 12.97 \\
\hline $\begin{array}{c}\text { Volatile solids content } \\
\text { (VS, \%) }\end{array}$ & 14.71 & 47.87 & 11.16 \\
\hline $\begin{array}{c}\text { Moisture content } \\
(\%)\end{array}$ & 80.50 & 49.97 & 87.03 \\
\hline $\begin{array}{c}\text { Ash (\%) } \\
\text { Total organic carbon } \\
\text { (TOC, \%) }\end{array}$ & 6.91 & 22.50 & 5.25 \\
\hline $\begin{array}{c}\text { Total nitrogen } \\
\text { (TN, \%) }\end{array}$ & 0.76 & 1.71 & 1.68 \\
\hline pH & 7.8 & 6.3 & 7.1 \\
\hline
\end{tabular}

\subsection{Anaerobic digestion test}

\subsubsection{Experimental design and setup}

The batch test uses a mixture of pure pig manure and pig manure and treated dead pigs as fermentation raw materials. The content of each component of the mixture is determined based on the mass and total solid content of the two components. The quality of the dead pigs in the five mixtures respectively accounts for the pigs. $3 \%, 6 \%$, $9 \%, 12 \%$, and $15 \%$ of feces were used to explore the effects of the content of dead pigs on fermentation.

Take a $500 \mathrm{~mL}$ glass bottle as a reactor, the amount of pig manure is determined by dead pigs and inoculum in each test group according to the initial TS load of the fermentation liquid is $80 \mathrm{~g} \mathrm{TS} / \mathrm{L}$, and the inoculum accounts for $30 \%$. After the inoculum was mixed with the substrate, distilled water was added to bring the effective volume of the fermentation broth to $400 \mathrm{ml}$. The upper part of all reactors were purged with nitrogen for five minutes before the start of the test and tightly closed with rubber septa and self-made steel sheets to ensure anaerobic conditions at the beginning of the test. In order to mix the fermentation broth in the reactor, all the reactors were placed in two constant temperature water bath oscillators, and the oscillation frequency was set to $100 \mathrm{r} / \mathrm{min}$.

At the same time, a blank reactor with only inoculum and water was started, and the biogas produced was measured to correct the effect of the inoculum on the gas production of each group [14]. All experiments were carried out at medium temperature digestion, and the reaction temperature was set at $35( \pm 1)^{\circ} \mathrm{C}$. After a period of reaction, no biogas produced within one week was used as a test end.

\subsubsection{Analytical method}

The total solids content (TS) and volatile solids content (VS) were tested by the drying method [15]. G. G. Li pointed out that total organic carbon (TOC) was about $47 \%$ of organic matter [16], TOC $=0.47 \times \mathrm{VS}$, total nitrogen (TN) was determined by $\mathrm{H}_{2} \mathrm{SO}_{4}-\mathrm{H}_{2} \mathrm{O}_{2}$ digestion and titration [17], the $\mathrm{pH}$ of the fermentation was measured using a magnetic resonance PHS-25.

The biogas produced by each reactor is collected by using $1 \mathrm{~L}$ gas bag every day. The gas bag is replaced every day, and the gas production is measured by using a syringe. The composition of the biogas (methane content) is passed through gas chromatography (GC122, Shanghai Jingke). The measurement was carried out, and two repeated measurements were taken each time. The biogas sample was withdrawn from the gas collection bag with a $10 \mathrm{~mL}$ gas-tight syringe and then injected into the gas chromatograph.

\subsection{Statistical analysis and data processing}

\subsubsection{Statistical analysis}

In the test, biogas production and methane content vary with reaction time, so the weighted average methane content (WA) throughout the reaction period is calculated using Equation (1) [18]: 


$$
W A(\%)=\frac{\sum_{i-1}^{n} D B P_{i} \times M P_{i}}{\sum_{i-1}^{n} D B P_{i}}
$$

Based on the average methane content, the standard deviation (STDV) is calculated according to Equation (2) [19]:

$$
S T D V=\sqrt{\frac{\sum\left(M P_{i}-W A\right)^{2}}{n-1}}
$$

among them:

$D B P_{i}$ : Biogas production on day $\mathrm{i}$

$M P_{i}$ : Methane content on day $\mathrm{i}$

$\mathrm{n}$ : Reaction days

\subsubsection{Data processing}

One-way ANOVA can be used to determine the differences in biogas production, methane production, and TS removal rates among different experimental groups. SAS software is used for one-way ANOVA and multiple t-test calculations [20] then $p$ values of different test groups can be obtained. The least significant difference (LSD) is used to judge whether the difference between two or more average values is significant or not significant. The formula for calculating LSD is as follows [21]:

$$
L S D=t \sqrt{\frac{2 M S E}{n}}
$$

among them:

$t$ : the required value for the degree of freedom error and significance level

MSE: Error Mean Square

$\mathrm{n}$ : number of trial repetitions

\subsection{Modified Gompertz model}

The gas production and microbial activity are closely related. The microbial growth model is a typical S-type three-parameter equation. As shown in Equation (4), the growth rate of the Gompertz equation curve is positive, and the curve shape is closely related to the equation parameters [22].

$$
y(t)=a * \exp [-\exp (b-c * t))]
$$

The parameters $a, b$, and $c$ in the equation are not biologically significant, so the equations are modified in a targeted manner, which can be used to fit the biogas fermentation kinetic model [12], and then analyse the proportion of dead pigs added to the gas production. Impact, the final Modified Gompertz model equation is as follows:

$$
y(t)=H_{m} * e^{-e^{\frac{R m}{H} * e *(\lambda-t)+1}}
$$

among them:

$y(t)$ : cumulative gas production at time $t$

$\mathrm{Hm}$ : maximum cumulative gas production

$\mathrm{Rm}$ : maximum gas production rate

$\lambda$ : residence time

\section{Result}

\subsection{Biogas production rate}

The average daily biogas productivity (L/kg VS day) of each test group is shown in Figure 1. For all fermented feedstocks, the first peak of biogas productivity can be observed on the second day after the start of the reaction, pure pig manure. The maximum biogas productivity was observed on the 25th day of the test group with the ratio of $3 \%, 6 \%$ and $9 \%$ to the dead pigs, which were 19.08 , $26.98,24.94$ and 20.18 (L/kg VS day), respectively. In the last two groups, the maximum biogas productivity was observed around day 61, which was 22.02 and 24.41 (L/kg VS day), respectively. The high addition ratio prolongs the gas production cycle, and the peak appearance may be due to the tolerance of microorganisms to the oil level. When the oil content is higher, the microorganisms need a certain domestication time.

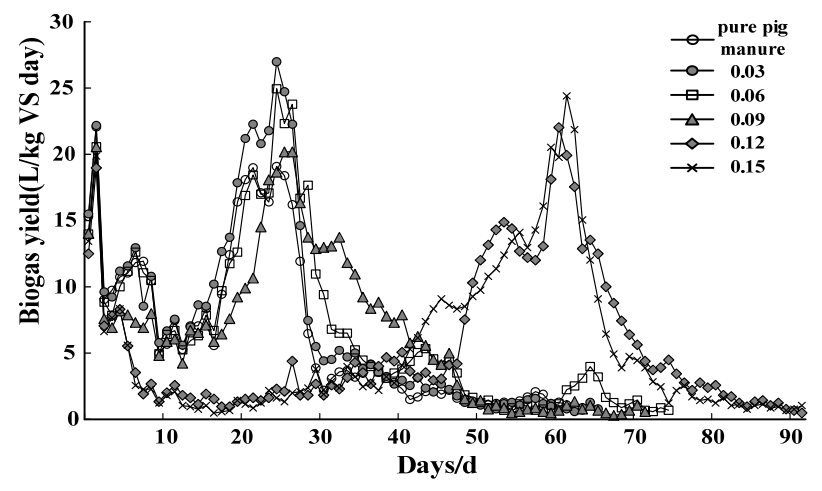

Fig. 1. Daily biogas production rates

\subsection{Biogas production}

The biogas production (L/kg VS) of each test group is shown in Figure 2. The biogas output of pure pig manure is 166.89 (L/kg VS). The mixed raw materials added with dead pigs have higher biogas production, and the whole digestion cycle is down. The biogas production of each group was 193.37, 201.44, 191.39, 202.44 and 198.45 (L/kg VS), respectively. The time required for the six test groups to reach $80 \%$ of the total gas production of biogas was 28, 28, 34, 36, 65 and 63 days, respectively (Table 2). 
Table 2. Correlation measurement and calculation index(standard deviations in parentheses)

\begin{tabular}{|c|c|c|c|c|c|c|}
\hline & $\begin{array}{l}\text { Pure pig } \\
\text { manure }\end{array}$ & $3 \%$ & $6 \%$ & $9 \%$ & $12 \%$ & $15 \%$ \\
\hline $\begin{array}{l}\text { Biogas production } \\
(\mathrm{L} / \mathrm{kg} \text { VS) }\end{array}$ & $\begin{array}{l}166.89 \\
(5.96)\end{array}$ & $\begin{array}{l}193.37 \\
(7.18) \\
\end{array}$ & $\begin{array}{l}201.44 \\
(6.21) \\
\end{array}$ & $\begin{array}{l}191.39 \\
(5.61) \\
\end{array}$ & $\begin{array}{l}202.44 \\
(5.21)\end{array}$ & $\begin{array}{l}198.45 \\
(5.62)\end{array}$ \\
\hline $80 \%$ biogas days & 28 & 28 & 34 & 36 & 65 & 63 \\
\hline $\begin{array}{l}\text { Methane production } \\
\text { (L/kg VS) }\end{array}$ & $\begin{array}{l}78.51 \\
(1.33)\end{array}$ & $\begin{array}{l}97.99 \\
(1.74)\end{array}$ & $\begin{array}{l}101.42 \\
(1.51)\end{array}$ & $\begin{array}{l}80.06 \\
(1.08)\end{array}$ & $\begin{array}{l}92.18 \\
(1.27)\end{array}$ & $\begin{array}{l}88.45 \\
(1.37)\end{array}$ \\
\hline $\begin{array}{l}80 \% \text { methane amount } \\
\text { days }\end{array}$ & 29 & 29 & 34 & 38 & 66 & 65 \\
\hline $\begin{array}{l}\text { Average methane } \\
\text { content }(\%)\end{array}$ & $\begin{array}{c}47.04 \\
(12.04) \\
\end{array}$ & $\begin{array}{c}50.67 \\
(12.49) \\
\end{array}$ & $\begin{array}{c}50.35 \\
(12.65) \\
\end{array}$ & $\begin{array}{c}41.83 \\
(10.04) \\
\end{array}$ & $\begin{array}{c}45.53 \\
(12.87) \\
\end{array}$ & $\begin{array}{c}44.57 \\
(13.31) \\
\end{array}$ \\
\hline $\mathrm{pH}$ & $\begin{array}{c}7.495 \\
(0.038)\end{array}$ & $\begin{array}{c}7.421 \\
(0.041)\end{array}$ & $\begin{array}{c}7.422 \\
(0.028)\end{array}$ & $\begin{array}{c}7.596 \\
(0.274)\end{array}$ & $\begin{array}{c}7.631 \\
(0.073)\end{array}$ & $\begin{array}{c}7.550 \\
(0.030)\end{array}$ \\
\hline VS removal rate (\%) & $\begin{array}{l}49.19 \\
(0.88)\end{array}$ & $\begin{array}{l}48.23 \\
(2.62)\end{array}$ & $\begin{array}{l}47.70 \\
(2.15)\end{array}$ & $\begin{array}{l}43.54 \\
(2.86)\end{array}$ & $\begin{array}{l}49.03 \\
(6.51)\end{array}$ & $\begin{array}{l}42.05 \\
(2.56)\end{array}$ \\
\hline
\end{tabular}

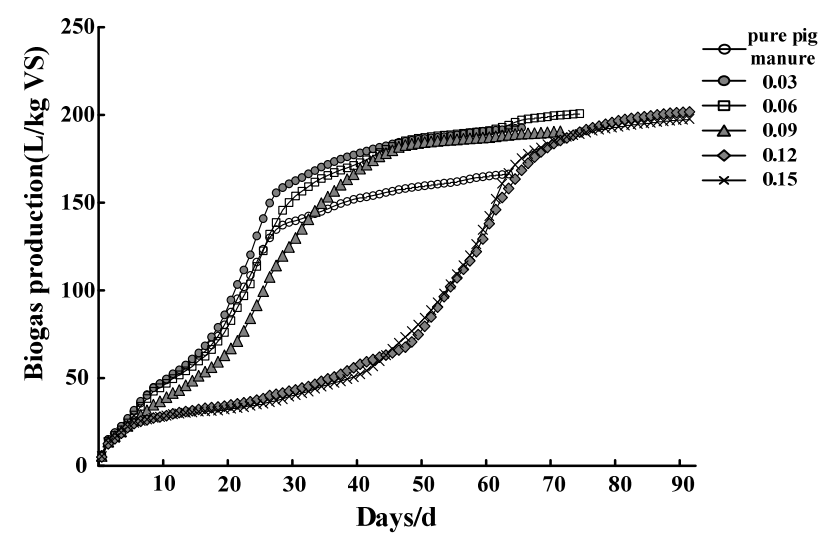

Fig. 2. Biogas production rates

\subsection{Biogas composition}

The methane content in the biogas of each test group is shown in Figure 3. Each data point is the average value of repeated measurements in each reactor. The methane content in the initial stage of the reaction is low. After a period of rapid rise, the maximum value is reached. The maximum methane content of feces was $64.8 \%$, and the maximum methane content of each experimental group added with sick pigs was $67.03,66.09,51.79,64.72$ and $65.94 \%$, respectively. The proportion of low methane content in the two groups was $12 \%$ and $15 \%$. The first four groups were extended for about 30 days, and the methane content of each group decreased at the end of the reaction and remained at a medium level.

After calculation, the relevant values are shown in Table 2. The average methane production of each group is $78.51,97.99,101.42,80.06,92.18$ and $88.45(\mathrm{~L} / \mathrm{kg} \mathrm{VS})$, respectively. The time required to reach $80 \%$ of the total methane production is 29 respectively. $29,34,38,66$, and 65 days, while the weighted average methane content was $47.04,50.67,50.35,41.83,45.53$, and $44.57 \%$, respectively.

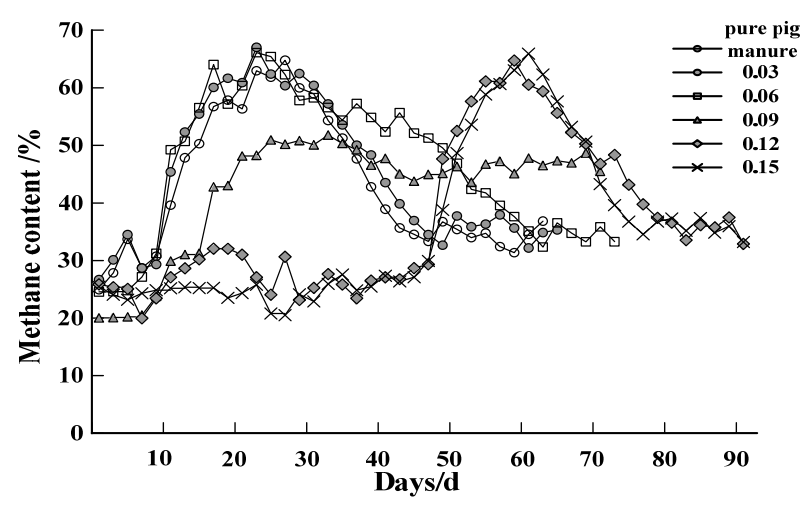

Fig. 3. Methane content of the biogas produced

\section{$3.4 \mathrm{pH}$ and volatile solids removal rate}

The effluent $\mathrm{pH}$, TS and VS of each group were stable in the test. As shown in Table 2, the effluent $\mathrm{pH}$ was between 7.392 and 7.631, the effluent TS was between 45 and 52 $(\mathrm{g} / \mathrm{L})$, and the effluent VS was between 31 and $36(\mathrm{~g} / \mathrm{L})$. After calculation, the VS removal rates of each group were $49.19,48.23,47.70,43.54,49.03$ and $42.05 \%$, respectively, and the volatile solid removal effect was better.

\section{Discussion}

\subsection{Effect of the proportion of dead pigs on biogas production and production rate}

Apparently, compared with pure pig manure, the biogas production of anaerobic digestion of mixed raw materials is higher. Therefore, it is assumed that the effect of the proportion of dead pigs on biogas production is not significant. The $\mathrm{P}$ value of biogas production by variance analysis is obtained. 0.8239 , the calculated value of LSD is $\operatorname{LDS}_{05}=76.82 \mathrm{~L} / \mathrm{kg} \mathrm{VS}, \mathrm{LDS}_{01}=116.4 \mathrm{~L} / \mathrm{kg} \mathrm{VS}$ (Table 3). The statistical analysis shows that the original hypothesis is established, that is, whether or not the dead pigs are added and the proportion added is not for biogas production. The impact or impact is small. In the range of 
the addition ratio of this experiment, the addition of dead pigs does not inhibit the digestion and gas production, indicating that when the mixed raw materials are digested, more dead pigs are added, and the digested biogas production is not affected. C. Lin et al. studied the effects of adding dead pigs on biogas production in a fully mixed biogas fermenter running continuously at medium temperature [23]. Their results showed that compared with pure pig manure, sick pigs were used as fermentation raw materials. After the pig manure sewage was mixed, the system operation was stable, the daily gas production of biogas did not change significantly, and the methane content increased, so this supported the findings in this study.

The number of days required to reach $80 \%$ of the total biogas production is used as an indicator to influence the biogas production rate. The statistical analysis shows that the overall effect of the proportion of sick pigs added to the production rate is significant. After the addition ratio is greater than $9 \%$, the required number of days is large. Increase, the gas production rate is obviously slower, there is obviously a lag period, but when the addition ratio is less than or equal to $9 \%$, there is no significant difference at this time, indicating that in the range of 0 to $9 \%$, adding dead pigs will not inhibit biogas. The production. In the process of anaerobic fermentation initiation, the inoculum and fermentation raw materials need to undergo an adjustment and adaptation cycle. In this process, increasing the organic load will have an impact on the fermentation process [24], which also supports the results of this study, that is, death. The increase in pigs has had an impact on the start of the test, resulting in a longer lag period, which affects the rate of biogas production.

\subsection{Effect of the proportion of sick pigs added on biogas composition}

From the apparent point of view, the methane production of each group of dead pigs was higher than that of pure pig manure alone. The $\mathrm{P}$ value of methane production was 0.8083 by variance analysis. The calculated value of LSD was $\mathrm{LDS}_{05}=37.46(\mathrm{~L} / \mathrm{kg} \mathrm{VS}), \mathrm{LDS}_{0} 1=56.76(\mathrm{~L} / \mathrm{kg}$ VS) (Table 3), the maximum standard deviation during the whole digestion process can be estimated to be 1.74 . The statistical analysis shows that the original hypothesis is established, and the effect of the proportion of sick pigs on methane production was not significant.

After calculation, the average content of methane in each group was calculated. The average content of methane in the test group with the ratio of $3 \%$ and $6 \%$ was more than $8 \%$ of the pure pig manure fermentation test group, and the content was over $50 \%$, while the addition ratio exceeded $9 \%$. The average content of methane in the group was lower than that in the pure pig manure group, and the proportion of dead pigs had a significant effect on the methane content. On the whole, proper addition of a certain proportion of dead pigs can increase the methane content, so choosing a suitable addition ratio can improve the fermentation efficiency of the mixed raw materials. Comparing the research of C. Lin et al. and the statistics of Q. D. Zhang et al. [25], the daily average number of dead pigs in a pig farm accounted for about $1-1.5 \%$ of the daily average manure, which could cause the methane content to increase by about $9 \%$. The result is closer to the findings of this study.

\subsection{Effect of the proportion of dead pigs on $\mathrm{pH}$ and degradation rate}

Apparently, the $\mathrm{pH}$ of the effluent of each test group was stable and there was no significant difference. For statistical analysis, the $\mathrm{P}$ value was 0.4491 , and the calculated value of $\mathrm{LSD}$ was $\mathrm{LDS}_{05}=0.29, \mathrm{LDS}_{01}=0.44$, and the estimated value of the maximum standard deviation was 0.274 , indicating that the original hypothesis is established, adding dead pigs has no significant effect on the $\mathrm{pH}$ of the mixed raw materials.

The degradation rate of anaerobic digestion raw materials is represented by the volatile solid removal rate. The removal rate of volatile solids in each group is between $40 \%$ and $50 \%$. The apparent difference is small, assuming that there is no significant difference, statistics The analysis shows that the $\mathrm{P}$ value is 0.0299 , the calculated values of LSD are $\operatorname{LDS}_{05}=5.05 \%$ and $\mathrm{LDS}_{01}=6.92 \%$, all of which reject the null hypothesis. Therefore, there is a significant difference between the volatile solid removal rates of each group. The overall performance is adding dead pigs will have a significant effect on the removal rate of volatile solids, resulting in a decrease in the volatile solids removal rate of the compounded raw materials.

Table 3. Results of statistical analysis.

\begin{tabular}{|c|c|c|c|}
\hline & $\mathbf{P}$ & $\mathbf{L D S}_{\mathbf{0 5}}$ & $\mathbf{L D S}_{\mathbf{0 1}}$ \\
\hline $\begin{array}{c}\text { Biogas } \\
\text { production }\end{array}$ & 0.8239 & 76.82 & 116.4 \\
\hline $\begin{array}{c}\text { Methane } \\
\text { production }\end{array}$ & 0.8083 & 37.46 & 56.76 \\
\hline $\mathrm{pH}$ & 0.4491 & 0.29 & 0.44 \\
\hline VS removal rate & 0.0299 & 5.05 & 6.92 \\
\hline
\end{tabular}

\subsection{Modified Gompertz model results and applications}

The SPSS is used as a tool and the biogas daily cumulative gas production data of each test group was fitted to the Modified Gompertz model, and the kinetic parameters of the model were as shown in Table 4. 
Table 4. Gompertz kinetic parameters of each test group.

\begin{tabular}{|c|c|c|c|c|c|c|c|}
\hline & & $\begin{array}{c}\text { Pure pig } \\
\text { manure }\end{array}$ & $\mathbf{3 \%}$ & $\mathbf{6 \%}$ & $\mathbf{9 \%}$ & $\mathbf{1 2 \%}$ & $\mathbf{1 5 \%}$ \\
\hline \multirow{2}{*}{ Model parameter } & $\mathrm{a}$ & 4286 & 5042 & 5234 & 5261 & 8800 & 8827 \\
\cline { 2 - 8 } & $\mathrm{b}$ & 1.156 & 1.331 & 1.293 & 1.400 & 1.503 & 1.516 \\
\cline { 2 - 8 } Cumulative gas production (Hm, L/kg VS) & 170.35 & 197.88 & 203.18 & 202.27 & 335.49 & 334.10 \\
\hline Cure pig & $\mathbf{3 \%}$ & $\mathbf{6 \%}$ & $\mathbf{9 \%}$ & $\mathbf{1 2 \%}$ & $\mathbf{1 5 \%}$ \\
\hline Ganure & 129.35 & 161.13 & 145.83 & 137.43 & 83.79 & 85.03 \\
\hline Residence time ( $\lambda$ )/d & 1.85 & 15.81 & 14.15 & 13.21 & 7.99 & 8.04 \\
\hline Digestive cycle /d & 64 & 65 & 75 & 72 & 92 & 92 \\
\hline Correlation coefficient & 0.988 & 0.986 & 0.99 & 0.988 & 0.961 & 0.955 \\
\hline Actual gas production (L/kg VS) & 166.89 & 193.37 & 201.44 & 191.39 & 202.44 & 198.45 \\
\hline
\end{tabular}

The correlation coefficient of the model fitting indicates that there is a good correlation between the groups, and the relevant parameter indicators can be obtained accordingly. In general, the cumulative gas production and actual gas production of the model increased with the increase in the proportion of sick pigs. In the four groups of pure pig manure and addition ratios of $3 \%, 6 \%$ and $9 \%$, the cumulative gas production of the model is basically consistent with the actual gas production, which indicates that anaerobic digestion is more adequate in the case of less than $9 \%$. The utilization rate of raw materials is high and the lag period is short, all of which are less than 5 days. However, in the $9 \%$ and $15 \%$ groups, the actual gas production was about $60 \%$ different from the model prediction, and the lag period was longer, about 19 days, and the maximum gas production rate also showed a significant decrease, indicating a higher addition. At the ratio, the actual gas production was equivalent to that of the $9 \%$ group, and the methanogenic potential of the excess dead pigs was not released, and the higher concentration of dead pigs inhibited the previous anaerobic digestion. According to the theoretical calculation formula for the theoretical degradation of methane production by three major nutrients, the unit VSfatty methane production is 2.4 times that of carbohydrates and twice as much as protein, which is the highest methane production among the three major nutrients [26]. The dead pigs contain more fat, and the fat content has a greater impact on anaerobic digestion [27]. When investigating the effect of oil on anaerobic fermentation, it is concluded that the more oil in a certain concentration range, the longer the time required for full degradation, and the more biogas produced, the higher concentration of oil will inhibit, and the lag period will Extension, this also supports the findings in this study.

\section{Conclusion}

This study investigated the biogas production, methane production, average methane content and degradation rate of batch anaerobic digestion of pure pig manure and five kinds of pig manure and dead pigs during medium temperature fermentation. All batch digestion tests were continued until one week without gas production, which ensured complete anaerobic digestion of the matrices of all studies.

The results showed that compared with pure pig manure fermentation, adding a certain amount of dead pigs had no significant effect on anaerobic digestion of biogas production and methane production, but it would affect the methane content of the produced biogas, when appropriate proportions were added (3\% and 6\%), a higher content of methane can be obtained. In terms of the degradation rate of anaerobic digestion materials, the addition ratio will have a significant effect on the degradation rate, and the addition of dead pigs will result in a decrease in the overall degradation rate.

According to the results of the Modified Gompertz model, the proportion of dead pigs was below $9 \%$, the anaerobic digestion was sufficient, the lag period was short, and the raw material utilization rate was high. Therefore, based on the above data and conclusions, the ratio of 0 to $6 \%$ of dead pigs is recommended, which can obtain better anaerobic digestion effect and higher raw material utilization rate. 


\section{References}

1. X. H. Chen, H.G. Zhu, Transactions of the Chinese Society of Agricultural Engineering 23, 279 (2007). (in Chinese with English abstract)

2. L. W. Deng, Z. A. Chen, China Biogas 25, 23 (2007). (in Chinese with English abstract)

3. T. Zhang, M. D. Bu, W Geng, Chinese Journal of Ecology 31, 1241 (2012). (in Chinese with English abstract)

4. Q. C. Hu, X. Y. Tang, R. T. Ning, et al, Transactions of the Chinese Society of Agricultural Engineering 31, 1 (2015). (in Chinese with English abstract)

5. J. Mata-Alvarez, J. Dosta, M. S. Romero-Güiza, et al, Renewable \& Sustainable Energy Reviews 36, 412 (2014)

6. Y. J. Shen, L. X. Zhao, H. B. Meng, Journal of Agricultural Science and Technology 15, 167 (2013). (in Chinese with English abstract)

7. S. Luostarinen, S. Luste, M. Sillanpää, Bioresource Technology 100, 79 (2009)

8. C. S. Zhang, [D] Biogas production anaerobic digestion of food waste, (2013). (in Chinese with English abstract)

9. K. W. Liu, F. Cheng, H. J. Lin, et al, Spectroscopy and spectral analysis 29, 102 (2009). (in Chinese with English abstract)

10. L. Zhang, Y. W. Lee, D. Jahng, Bioresource Technology 102, 5048 (2011)

11. Z. H. Hu, H.Q. Yu, Waste Management 26, 1222 (2006)

12. J. C. Li, K. W. Sun, J. He, et al, Chinese Journal of Environmental Science 32, 1843 (2011). (in Chinese with English abstract)

13. X. W. Cheng, H. G. Zhu, T. Zhang, et al, China Biogas 34, 9 (2016). (in Chinese with English abstract)

14. H. G. Zhu, X. H. Chen, J. X. Tang, Transactions of the Chinese Society of Agricultural Engineering 23, 201 (2007). (in Chinese with English abstract)

15. Y. L. He, [M] China Light Industry press, (1998). (in Chinese with English abstract)

16. G. G. Li, [M] Chemical Industry press, (2003). (in Chinese with English abstract)

17. NY525, [S] The People's Republic of China Agricultural Industry Standards-Organic fertilizer, (2012). (in Chinese with English abstract)

18. H. M. El-Mashad, R. H. Zhang, Bioresource Technology 101, 4021 (2010)

19. Q. H. Li, J. Yu, J. Y. Liu, Metal Materials and Metallurgy Engineering 41, 45(2013). (in Chinese with English abstract)

20. H. X. Gao, [M] Peking University Press, (2009). (in Chinese with English abstract)

21. D. C. Montgomery, [M] Design and Analysis of Experiments. Y. S. Fu, J. Zhang, Z. Y. Wang, Y. Xie,
Translate, [M] Posts \& Telecom Press, (2009). (in Chinese with English abstract)

22. M. R. Zhu, Mathematics in Practice and Theory 32, 705 (2002) (in Chinese with English abstract)

23. H. L. Tian, C. Lin, H. Sun, et al, Renewable Energy Resources 32, 1869 (2014). (in Chinese with English abstract)

24. X. S. Shi, X. Z. Yuan, Z. L. Jia, et al, CIE SC Journal 65, 1862 (2014). (in Chinese with English abstract)

25. Q. D. Zhang, R. L. Geng, Y. Dai, China Animal Husbandry \& Veterinary Medicine 40, 232 (2013). (in Chinese with English abstract)

26. H. B. Møller, S. G. Sommer, B. K. Ahringb, Biomass \& Bioenergy 26, (485) 2004

27. J. L. Liao, [D] Study on the Influence of Grease on Biogas Production from Kitchen Wasterwater by Anaerobic Digestion, 2013. (in Chinese with English abstract) 